\title{
From Study-Abroad to Study-at-Home: Teaching Cross-Cultural Design Thinking During COVID-19
}

\author{
Mae M. Lewis and Mia K. Markey (1) \\ Department of Biomedical Engineering, The University of Texas at Austin, Austin, TX, USA
}

(Received 8 July 2020; accepted 10 August 2020; published online 1 September 2020)

\section{CHALLENGE STATEMENT}

Undergraduate degrees at The University of Texas at Austin (UT Austin) require "Flags" in each of six areas: (1) Cultural Diversity in the United States; (2) Ethics; (3) Global Cultures; (4) Independent Inquiry; (5) Quantitative Reasoning; and (6) Writing. Courses that carry the Global Cultures Flag guide students in exploring the practices, beliefs, and histories of at least one non-US cultural group, and encourage reflection on one's own cultural experiences. Many engineering students are excited to learn about global cultures in the context of their discipline through faculty-led study-abroad. ${ }^{8}$ Currently, there are 11 engineering courses carrying a Global Cultures Flag, 10 of which are faculty-led study-abroad. Unfortunately, the COVID-19 pandemic has prevented almost 400 of our engineering students from participating in faculty-led study-abroad. Our challenge was to quickly transition a faculty-led study-abroad carrying a Global Cultures Flag to an online format.

\section{NOVEL INITIATIVE}

The course "International Perspectives on Biomedical Engineering Design" prepares students for crosscultural design thinking. ${ }^{4}$ Students learn human-centered design methods to understand the people for whom they are designing and to identify actionable problem statements. ${ }^{3}$ The course theme is the potential of artificial intelligence (AI) to transform breast cancer care. As a short-term faculty-led study-abroad in

Address correspondence to Mia K. Markey, Department of Biomedical Engineering, The University of Texas at Austin, Austin, TX, USA. Electronic mail: mia.markey@utexas.edu
Portugal, it facilitates students' exploration of the impact of culture on healthcare delivery and the design of healthcare technologies. Reflective exercises are emphasized to help students develop intercultural competence. ${ }^{13}$ The primary course number is in Biomedical Engineering with cross-listings offered through Chemical Engineering and Mechanical Engineering.

Students plan, conduct, and interpret interviews with healthcare professionals who treat breast cancer patients at Champalimaud Clinical Center (Lisbon, Portugal) and The University of Texas MD Anderson Cancer Center (Houston, US). In study-abroad, at least half of the interviews are conducted via videoconference since half the professionals are in US and half are in Portugal. As an online course, all of the interviews are via videoconference. Due to scheduling constraints for synchronous online delivery, the number of healthcare professionals interviewed was reduced from 14 in the 2019 study-abroad offering to 10 in the 2020 online offering, with a corresponding decrease from 7 to 5 specialties. Study-abroad students' learning from the interviews is assessed in three ways: (1) individual reflective writing; (2) actionable problem statements written in the form of tweets by small groups $^{9}$ (Find us on Twitter at @ PovPractice.); and (3) NIH-style abstracts written, reviewed, and revised by small groups. Students are randomly assigned to different groups for different activities. For the 2020 online offering, four groups of four students each were used. Given the enrollment and distribution of majors, groups typically included a mix of BME and non-BME students. Individual reflective writing required students to summarize the interview experience by discussing three main ideas, answering the prompt: "How is the culture of the country in which the subject of this interview practices reflected in their answers to the interview questions?" and proposing a future interview 
question. Actionable problem statements capture needs and insights identified from interviews of healthcare professionals using tweetable memes. After all interviews were completed, students proposed and critiqued solutions to actionable problem statements in the form of NIH-style abstracts. For the transition to online, we maintained the first two assessments but dropped the third because the NIH-abstract project typically requires students to work together in groups for many hours. We were concerned about students' ability to coordinate extensive groupwork in the online format given the pandemic's disruptions of "normal" life, e.g., some students were expected to have increased family responsibilities. It is noteworthy that the online students' interview questions included the impact of the COVID-19 pandemic on breast cancer care and health equity topics inspired by the Black Lives Matter movement.

Study-abroad students visit the Breast Unit of two very different hospitals: Hospital de São João participates in the national health service whereas Champalimaud Clinical Center is a private institution. Study-abroad students also visit research facilities: Centro de Investigação em Tecnologias e Serviços de Saúde (CINTESIS), Associação Fraunhofer Portugal Research (Fraunhofer AICOS), and Instituto de Investigação e Inovação em Saúde (i3S). The online format replaced these site visits with "virtual field trips" featuring YouTube videos and readings and were assessed by discussion board posts relating them to other course activities.

Study-abroad students participate in structured cultural activities: short immersive Portuguese language lesson; hands-on introduction to cooking traditional Portuguese food; and an interactive lesson in traditional Portuguese dances. The Portuguese language lesson was replaced with a short course through the online language learning platform Memrise. In the online dancing lesson, students submit a video of themselves performing a traditional Portuguese dance and discuss how it compares to other dance forms. For this and other video assignments, students used FlipGrid, which integrates with Canvas, our learning management system. FlipGrid is a user-friendly platform for instructors to facilitate and moderate student video responses. The convenient privacy settings offer an advantage over self-recorded student videos by allowing instructors to limit influence from past assignments by hiding the responses. The settings can also be adjusted so that students can view and comment on each other's submissions. These video assignments also give the instructor the opportunity to hear from all students, which is an important interaction often lost in online instruction. Unlike written reflections, video reflections capture students' feelings in the moment and are a memorable course experience. ${ }^{12}$ In lieu of a hands-on cooking lesson, students read Portuguese recipes and respond with a reflective FlipGrid video submission about which ingredients they had at home and how the recipes compared to what they normally eat. Study-abroad students also go on guided tours. We did not try to replace the tours in the online format, but instead picked a few topics to introduce through readings, videos, and interactive websites, and assess by FlipGrid: geography of Portugal and its connection to wine industry; role of Portugal in Black History; and religious freedom.

Changes to students' thinking about culture, design, breast cancer, and AI in medicine were assessed by comparing start-of-course and end-of-course concept maps. ${ }^{1,7}$ Study-abroad students create concept maps in small groups, whereas the online students created maps individually. In the study aboard format, it was natural to have students do the concept maps in small groups because we had extensive class time together. For the online format, the amount of synchronous class time was very limited in comparison. Moreover, we were reluctant to assign group projects because we were concerned about students' ability to coordinate extensive groupwork in the online format given the pandemic's disruptions of "normal" life. For this reason, in the transition to online, we chose to change the concept map exercises from group projects to individual assignments.

Students individually perform start-of-course and end-of-course self-assessments of their Global Learning and their Intercultural Knowledge and Competence ${ }^{5,6}$ and respond to free-response reflection prompts inspired by the set proposed by the University of Michigan for international programs in engineering, ${ }^{10}$ though substantial modifications were made for the transition to online learning.

Students write three end-of-course essays. They use Rolfe's reflection mode ${ }^{11}$ to write about the impact of culture on healthcare delivery and the impact of culture on the design of healthcare technologies, especially those based on AI methods; this process was unchanged by the transition to online learning. However, in the study-abroad format, the third essay is a photo essay based on photographs they take during the program, so the online students searched for photos online.

\section{REFLECTION}

Six biomedical engineering majors and 10 students in other health-related disciplines enrolled (Biochemistry, Biology, Health \& Society, International Relations, Neuroscience, and Public Health.) The total is 
similar to prior study-abroad offerings, though the percentage of non-engineering majors was higher (historically $\sim 10-30 \%$.) About half of the students identified as male (7) and the others as female (9), which is typical for the course. As expected, they ranged from rising sophomores to graduating seniors.

Some key ideas typically noted from interviews conducted by study-abroad students were observed in the online format as demonstrated by the students' written reflections and actionable problem statements, e.g., differences between the US and Portuguese governments' roles in healthcare. However, the online students' questions emphasized more current events, e.g., how COVID-19 is impacting breast cancer care and how AI may perpetuate health inequities. In contrast, study-abroad students' questions emphasized the doctors' daily experiences and their reflective writings stressed the emotional impact on the doctors. We believe that these differences are more likely due to the extraordinary world events that the students are living through rather than the course format.

Recording interviews was essential because connections were frequently "dropped" and students faced pandemic time demands (health concerns, family responsibilities, etc.) Video recordings of course sessions can be shared on Canvas via Zoom or Panopto. While either allows the instructor to disable download and restrict access by date, we decided to use Panopto because the Zoom configuration at our institution does not enable the instructor to restrict access to students enrolled in the course. In particular, students enrolled in a course can share links to course recordings distributed via Zoom to any member of our large university, whereas course recordings distributed via Panopto cannot be simply shared to people not enrolled in the course. Considering the privacy of both our students and professional guests, we prefer greater access control.

The study-abroad professional field trips were difficult to mimic online. Many Portuguese organizations have YouTube channels, but often with limited English-language content. YouTube's automatic translations from spoken Portuguese to English subtitles were not useable. Unfortunately, our virtual field trips did not prompt as much critical reflection. For example, the visit to Hospital de São João is a major culture shock to many of our study-abroad students because it challenges their assumptions about what a "good" hospital looks like. In contrast, the students' video reflections about the virtual field trip to Hospital de São João were not emotional. We believe that this is a substantial loss in the translation from study-abroad to online.

Online language learning was well-received, and some students exceeded the requirements. In future courses, online or study-abroad, Memrise may be beneficial for students to pace their own language learning.

Students seemingly enjoyed FlipGrid. Their video reflections were longer and more engaging than their discussion posts. Video assignments were also opportunities to involve others in their learning. In the cooking FlipGrid, many students reported discussing, sharing, or cooking a meal with family. Family members or pets also served as dance partners - some more willingly than others! Shared experiences with family can make it easier to reflect after a course is over, which is key to a successful study-abroad. ${ }^{2}$ However, these observations may not generalize to post-pandemic online offerings. Due to the societal impacts of the pandemic, students are currently spending more time with their families than with fellow students.

While the online cultural activities related to geography, history, and governance are limited substitutes for the extensive educational tours of study-abroad, there were complementary learning benefits. For example, some students had not realized the relative size of Portugal to its former colonies prior to the interactive map activity. We recommend using more multi-media tools in future offerings, including for study-abroad. A key cultural experience for studyabroad students is the São João festival. In the end-ofcourse self-reflections, several online students regretted missing the São João festival. Online information about festival traditions is a far cry from participation. Moreover, in the future we will explore online approximations of the informal interactions with Portuguese people experienced in study-abroad.

Broadly, the learning gains qualitatively assessed using concept maps were similar for the online offering as compared to the prior study-abroad offerings. ${ }^{4}$ However, our online students emphasized the risk that AI poses to perpetuate or increase racial and socioeconomic biases. We suspect that this is due to concurrent world events rather than course format. Some COVID-19 specific themes were also evident, e.g., interest in clinicians' descriptions of breast cancer patients' isolation due to pandemic constraints on visitors. Since online submission of concept maps was effective, we will adopt it for future offerings, including study-abroad.

For Global Learning Value Rubric ${ }^{5}$ self-assessments, students' end-of-course scores were significantly improved (Wilcoxon Signed Rank Test) relative to start-of-course for Global Self-Awareness $(p<0.01)$ and Perspective Taking $(p<0.01)$, but not for Cultural Diversity $(p=0.35)$, Understanding Global Systems $(p=0.22)$, Applying Knowledge to Contemporary Global Contexts $(p=0.11)$, or Personal and Social Responsibility $(p=0.51)$. For Global Self- 
Awareness, the most common response on the start-ofcourse self-assessment was "Analyzes ways that human actions influence the natural and human world," whereas the most common response on the end-ofcourse self-assessment was "Effectively addresses significant issues in the natural and human world based on articulating one's identity in a global context." For Perspective Taking, the most common response on the start-of-course self-assessment was "Identifies and explains multiple perspectives (such as cultural, disciplinary, and ethical) when exploring subjects within natural and human systems," whereas the most common response on the end-of-course self-assessment was "Evaluates and applies diverse perspectives to complex subjects within natural and human systems in the face of multiple and even conflicting positions (i.e., cultural, disciplinary, and ethical.)"

For Intercultural Knowledge and Competence Value Rubric $^{6}$ self-assessments, students' end-of-course scores were significantly improved (Wilcoxon Signed Rank Test) relative to start-of-course for Empathy $(p<0.01)$, but not for Cultural Self-awareness $(p=0.13)$, Knowledge of Cultural Worldview Frameworks $(p=0.12)$, Verbal and Nonverbal Communication $(p=0.63)$, Curiosity $(p=0.11)$, and Openness $(p=0.77)$. In contrast, the prior studyabroad cohort self-reported improvements in all areas except Personal and Social Responsibility. ${ }^{4}$ For Empathy, the most common response on the start-ofcourse self-assessment was "Recognizes intellectual and emotional dimensions of more than one worldview and sometimes uses more than one worldview in interactions," whereas the most common response on the end-of-course self-assessment was "Interprets intercultural experience from the perspectives of own and more than one worldview and demonstrates ability to act in a supportive manner that recognizes the feelings of another cultural group."

The Global Learning Value Rubric ${ }^{5}$ and Intercultural Knowledge and Competence Value Rubric ${ }^{6}$ selfassessments suggest global cultures topics that are more challenging to address online relative to studyabroad. However, in addition to the limitations of selfassessments, taking a course online during a pandemic is not the same as taking a course online in general, e.g., some students reported that the current situation at home made it harder to think about global issues whereas others said that the ongoing pandemic made global issues more salient.

Study-abroad students have extensive opportunities for informal feedback because they spend many hours with the instructors. While we endeavored to be readily available to online students via Slack, interactions were still limited by comparison. Hence, the online distribution of structured rubrics was essential.

Several online students lamented that they did not get to know their classmates. In contrast, study-abroad students form strong bonds. Weaker connections among students are detrimental to learning because each person views the world through the lens of their own experiences, e.g., students' responses to readings about religious freedom varied with their own religious background. In addition, we hypothesize that weaker connections among students decreased their efficiency in using remote collaboration tools for cooperative learning activities, e.g., generating actionable problem statements. In future online offerings, we will promote more student discussion towards the goal of increasing appreciation of the cultural diversity within the US and how one's personal experiences influence one's perceptions of Portugal. We propose to build rapport among the students by having them interview each other, through which they would also be practicing skills they need to interview the healthcare professionals. This approach could be easily repeated throughout the course as new interview techniques are introduced.

The online version of the class retained some of the major learning objectives in AI, breast cancer, and the role of culture in healthcare delivery and design of healthcare technologies through interviews, discussion board posts, concept maps, and tweetable actionable problem statements. In addition, FlipGrid video reflections helped us maintain some of the authenticity of Portuguese cultural experiences such as cooking traditional food, dancing to folk music, and learning facts about Portuguese culture. Students who incorporated members of their families into these assignments may benefit from creating lasting memories at home. However, study abroad experiences relying more heavily on students' interactions with each other and with Portuguese people were not captured in this online format. The Global Value Learning Rubric and Intercultural Knowledge and Competence Value Rubric self-assessments show that global cultures topics were more challenging to address, although these findings may also be influenced by the current extraordinary world events rather than solely the shift to online learning. Final course surveys also showed that students wished they had taken more initiative to meet their classmates. Moving forward, study-abroad courses that must transition to an online format should incorporate more opportunities for student interaction to increase overall student experience and student appreciation for others' diverse perspectives on course material. 


\section{ACKNOWLEDGMENTS}

We thank the International Engineering Education office at The University of Texas at Austin for the opportunity to teach International Perspectives on Biomedical Engineering Design in the Maymester format. We are particularly grateful for the guidance of our program coordinator, Ellen Aoki. We deeply appreciate the support of our colleagues at Champalimaud Clinical Centre in Lisbon, especially Maria João Cardoso and Sofia Bragança. We thank Patricia Padrão at Universidade do Porto for Portuguese recipes. We are indebted to the healthcare professionals who graciously volunteered their time to be interviewed by our students. We also appreciate the technical support and guidance in transitioning to teaching online from our colleagues, especially Kathy Jackson, Jim Pollard, and Dan Puperi.

\section{AUTHOR CONTRIBUTIONS}

Both authors contributed to all aspects of the manuscript.

\section{REFERENCES}

\footnotetext{
${ }^{1}$ Adesope OO, Nesbit JC. A systematic review of research on collaborative learning with concept maps. In: Handbook of research on collaborative learning using concept mapping. Hershey: IGI Global; 2009. pp. 238-55.

${ }^{2}$ Davis K, Knight DB. Impact of a global engineering course on student cultural intelligence and cross-cultural communication. J Int Eng Educ. 2018;1:4.

${ }^{3}$ Doorley S, Holcomb S, Klebahn P, Segovia K, Utley J. Design thinking bootleg. Palo Alto: Stanford d.school; 2018. https://dschool.stanford.edu/resources/design-thin king-bootleg. Accessed 5 July 2020.
}

${ }^{4}$ Ferreira MF, Savoy JN, Markey MK. Teaching crosscultural design thinking for healthcare. Breast. 2020;50:110.

${ }^{5}$ Global Learning VALUE Rubric. In: Association of American Colleges \& Universities. https://www.aacu.org/ value/rubrics/global-learning. Accessed 5 July 2020.

${ }^{6}$ Intercultural Knowledge and Competence VALUE Rubric. In: Association of American Colleges \& Universities. h ttps://jitp.commons.gc.cuny.edu/reflecting-on-reflections-u sing-video-in-learning-reflection-to-enhance-authenticity/. Accessed 5 July 2020.

${ }^{7}$ Kinchin IM. Concept mapping as a learning tool in higher education: a critical analysis of recent reviews. J Contin High Educ. 2014;62:39-49.

${ }^{8}$ Klein-Gardner S. Defining global competence for engineering students. In: 2011 ASEE annual conference \& exposition; June 26-29. Vancouver, BC: American Society for Engineering Education; 2011.

${ }^{9}$ Markey MK, Monteiro JC, Stewart J. Using Twitter to support students' design thinking. In: ASEE gulf-southwest section annual meeting; April 4-6. Austin: American Society for Engineering Education; 2018. pp. 4-7.

${ }^{10}$ Reflection Prompts - International Programs in Engineering. In: Michigan Engineering International Programs in Engineering. https://ipe.engin.umich.edu/studyabroad/pre departureinfo/yourstory/reflection-prompts/. Accessed 3 July 2020.

${ }^{11}$ Rolfe G, Freshwater D, Jasper M. Critical reflection for nursing and the helping professions a user's guide. London: Palgrave Macmillan; 2001.

${ }^{12}$ Rose EJ, Sierschynski J, Björling EA. Reflecting on reflections: Using video in learning reflection to enhance authenticity. J Interact Technol Pedagogy. 2016.

${ }^{13}$ Vande Berg M, Michael Paige R, Hemming Lou K, editors. Student learning abroad: what our students are learning, what they're not, and what we can do about it. Sterling: Stylus Publishing, LLC; 2012.

Publisher's Note Springer Nature remains neutral with regard to jurisdictional claims in published maps and institutional affiliations. 